\title{
Hermenéutica, intertextualidad y referencias a la política. Observaciones sobre traducciones de Rainer Maria Rilke, Bertolt Brecht y Günter Grass
}

\author{
Alberto Vital \\ Universidad Nacional Autónoma de México \\ albertovita104@yahoo.com.mx
}

Recibido: 23 de octubre de 2012

Aceptado: 4 de marzo de 2013

\section{RESUMEN}

En el presente artículo se discuten pasajes de traducciones existentes de Rilke, Brecht y Grass a la par que se presenta el contexto histórico-discursivo de las respectivas obras. La extrema riqueza del lenguaje rilkiano requiere la atención a formas fonéticas y gramaticales, mientras que la hermenéutica literaria facilita la comprensión. Brecht establece en las Elegías de Buckow una relación intertextual con Rilke, aun subvirtiendo el género elegíaco. En el poema Die Lösung, motivado por los acontecimientos del 17 de junio de 1953, el traductor se enfrenta a la auto ironía del autor. El gusto por inmiscuirse con asuntos del momento es compartido por Grass. Politische Landschaft es un poema que, siendo en su primer momento muy legible, se vuelve arduo fuera del horizonte político original.

Palabras clave: Traducción, Rilke, Brecht, Grass, Hermenéutica, Intertextualidad, Política.

Hermeneutics, Intertextuality and References to Politics. Observations on Translations of Rainer Maria Rilke, Bertolt Brecht and Günter Grass

\begin{abstract}
The present article discusses passages of existing translations of Rilke, Brecht and Grass, considering the respective historical and discursive contexts of the works. The extreme richness of Rilkean language requires attention to phonemes and grammatical forms while literary hermeneutics facilitates comprehension. In his Buckow Elegies, Brecht establishes a relation of ironic intertextuality with Rilke but he subverts the genre by incorporating references to the political context of his time. The poem "Die Lösung", motivated by the occurrences of the $17^{\text {th }}$ of Juny 1953, displays the author's auto irony. Also Grass intervenes fre-


quently on political matters. "Politische Landschaft" is one of his poems that being initially very legible, turns arduous when received outside of its former political context.

Keywords: Translation, Rilke, Brecht, Grass, Hermeneutics, Intertextuality, Politics.

Sumario: 1. Rilke: análisis de traducciones. 2. Brecht: relación con Rilke. 2.1. Análisis de traducciones. 3. Grass: relación con Brecht. 3.1. Elaboración y análisis de traducciones.

\section{Rilke}

Paul de Man se preguntaba por qué es tan grande el impacto internacional de Rainer María Rilke (1875-1926), pues no se trata de un autor fácil y mucho menos complaciente. No fue un poeta que se inscribiera en una moda que lo codificara y nos ayudara a una pronta comprensión y ubicación, incluso clasificación: su poesía es intrincada, muy sugerente, desafiante ya para el lector de lengua alemana. No es, en suma, sencilla la respuesta a la pregunta del estudioso de la literatura y teórico del deconstructivismo.

Por lo pronto, De Man ofrece un análisis de uno de los poemas más o menos tempranos ("Am Rande der Nacht", "A la orilla de la noche", de una primera versión de El libro de horas) y muestra allí la extrema riqueza del lenguaje de Rilke, y esa riqueza automáticamente lo vuelve muy difícil de traducir. De Man aporta un ejemplo de juego con la frecuencia de fonemas en la construcción y ratificación del sentido ya en este texto de un joven poeta maduro, quien a los 30 años de edad se abocaba a los grandes temas y procedimientos poéticos de su poesía definitiva:

El momento de síntesis corresponde exactamente a la modulación de las asonancias que van desde el sonido $i$ (repetido diez veces en los primeros ocho versos) al sonido $e$ (repetido diez veces en los últimos cuatro versos) (De Man. Alegorías de la lectura. 1990: 49) ${ }^{1}$.

Este poema no aparece en la edición española de El libro de horas, de Federico Bermúdez-Cañete (1905, reedición 2005). En todo caso, Rilke es un poeta generosamente traducido al español. Sin posible duda, las Duineser Elegien es el libro con más posibilidades de lectura entre nosotros en el corpus de este autor $\mathrm{y}$, probablemente, de toda la poesía en lengua alemana. Aquí me concentraré en la comparación de un solo pasaje de la décima y última elegía. Se trata del momento final:

Und wir, die an steigendes Glück denken, empfänden die Rührung,

${ }^{1}$ En mi comunicación de 2011 para la Cátedra José Gaos recordé la importancia del análisis lingüístico en general y del análisis de la frecuencia de fonemas en particular para una mejor comprensión del sentido en el texto literario, sobre todo el poético. 
die uns beinah bestürzt, wenn ein Glückliches fällt (Duineser Elegien 1966: 482).

Palabra por palabra, wortwörtlich, lo podríamos verter de la siguiente manera:

Und wir, die an steigendes Glück

[Y nosotros, que en ascendente felicidad]

denken, empfänden die Rührung,

[pensamos, sentiríamos la conmoción]

die uns beinah bestürzt,

[que a nosotros casi consterna]

wenn ein Glückliches fällt

[cuando algo feliz cae].

De Man señala que uno de los ejes decisivos en la poesía de Rilke es justamente la oposición complementaria entre arriba y abajo. Por su parte, Jacques Derrida se basa en una interpretación de Hans Georg Gadamer para ensayar el análisis de un hermético poema de Paul Celan a partir del último verso. Arrancar con el último verso puede en un momento dado ser la clave para que comprendamos mejor el texto, para que iluminemos ejes del poema (Derrida. Béliers. Le dialogue interrompu: entre deux infinis, le poème. 2003).

Aquí estamos ante la última estrofa de las Duineser Elegien, y en ellas efectivamente aparece la oposición señalada por De Man, mediante las dos cursivas determinadas por el propio autor y transmitidas sin asomo de duda por su editor original Ernst Zinn. Pero no se trata aquí de pretender un esclarecimiento de este libro culminante, sino simplemente de mostrar y comparar un puñado de traducciones al español de una estrofa decisiva de la poesía contemporánea. De ese modo tendremos la posibilidad de hacer un breve repaso de la poesía de Rilke por medio de uno de sus momentos característicos y tendremos la oportunidad de ver, mediante un muestreo sancionado heurísticamente por la cita de Derrida, cómo lo han tratado en nuestro idioma.

En Nueva antología poética, el traductor Jaime Ferreiro Alemparte propone lo siguiente:
Y nosotros, que pensamos en una felicidad
creciente, sentimos la emoción
que casi nos anonada
cuando algo feliz se derrumba (239).

Se imponen dos observaciones: en alemán dice "empfänden", esto es, "sentiríamos". Este tiempo-modo hipotético conecta la última estrofa con la penúltima, la cual incluye dos verbos conjugados de la misma manera. Véase esta traducción palabra por palabra:

Aber erweckten sie uns, die unendlich Toten, ein Gleichnis,

[Pero si despertaran ellos en nosotros, $\{$ ellos $\}$, los infinitamente 
muertos, un símil]

siehe, sie zeigten vielleicht auf die Kätzchen der leeren

[mira, ellos apuntarían quizá a los amentos de los vacíos]

Hasel, die hängenden, oder

[avellanos, los colgantes, o]

meinten den Regen, der fällt auf dunkles Erdreich im Frühjahr.

[aludirían a la lluvia que cae sobre oscura tierra en primavera].

De ese modo, hay una continuidad gramatical que coloca el remate en un terreno hipotético. Esta salida meramente gramatical nos conduce a un concepto del propio Jacques Derrida, el de indecidibilidad. En efecto, Rilke mantiene en un plano cuidadosamente potencial, posible, virtual, un movimiento brusco dentro del eje que señala De Man; las dos palabras en cursivas apuntan justamente a un ascenso (steigendes: ascendente o creciente) y a un descenso (fällt: cae). Estas cursivas indican hasta qué punto el autor quiso dejar huella de su conciencia y de su deseo de que los lectores tuviéramos esa misma conciencia acerca de la importancia de dicho eje tanto como del movimiento brusco de caída, el cual sin embargo se mantiene en un terreno hipotético. A propósito de los indecidibles según Derrida, escribe Amalia Quevedo:

Derrida demuestra que es posible invertir el binarismo metafísico, trastocar la jerarquía, privilegiando el segundo término de la oposición: el cuerpo sobre la mente, el hombre sobre Dios, lo complejo sobre lo simple, la ausencia sobre la presencia. El propio Derrida lo hace; pero, para desestabilizar el binarismo y dislocar la oposición, apela a algo que funciona de modo distinto, a los indecidibles. La indecibilidad destruye las estructuras binarias del pensamiento metafísico, disloca la estructura aut-aut de la oposición. Lo indecidible juega de todas las maneras, no está de ningún lado, no puede ser fijado. Lo indecidible no enfrenta un término fundacional privilegiado con un término inferior subordinado. Desfijar esta certeza es desfijar la metafísica (Quevedo 2012).

En resumen, el final de las Elegías de Duino se ubica en lo que no se puede decidir. Se ubica asimismo en lo ondulante u oscilatorio de la condición humana. Nuestra condición se mueve, sí, sin cesar entre la cresta y el derrumbe. Aun así, este final debe mantener a toda costa el hipotético, el cual apunta a lo no decidible del mundo de los muertos y de los muertos mismos, sobre los cuales se sustenta todo el pasaje, al ser ellos evocados y presentados en una situación hipotética ante nosotros.

La segunda observación es tanto la falta de dramatismo como el efecto contundente de la palabra final: fällt, la cual es simplemente "cae". El ritmo se corta abruptamente para dar el efecto de caída no sólo en el plano del significado, sino en el más amplio conjunto del sentido. Por eso es mejor traducir "cae" y colocar la palabra al final, aun cuando en alemán este final es obligatorio por razones gramaticales.

La palabra Gleichnis de la penúltima estrofa es asimismo importante, no sólo porque resume la acción que llevarán a cabo los unendlich Toten ("los infinitamente muertos"), sino porque se refiere asimismo a la posibilidad de equivalencia entre el mundo de los vivos y el mundo de los muertos. Esta equivalencia es un río sub- 
terráneo de las Elegías: ¿a qué equivale en el mundo de los muertos cada cosa del mundo de los vivos? Este río, explícito en un pasaje de la décima elegía, desemboca en la palabra Gleichnis, que Ferreiro Alemparte vierte como "símil". Lorenza Fernández del Valle y Juan Carvajal hacen lo mismo:

Pero si los infinitos muertos despertaran en nosotros un símil, Mira: señalarían quizá las florecillas colgantes del desnudo avellano, o bien aludirían a la lluvia primaveral sobre el oscuro reino terrestre.

Y nosotros, que pensamos en una dicha creciente, sentiríamos la emoción que casi nos espanta cuando algo feliz cae (2004: 91).

Gleichnis es, según el Duden, eine "kurze bildhafte Erzählung, die einen abstrakten Gedanken oder Vorgang durch Vergleich mit einer anschaulichen, konkreten Handlung [mit belehrten Absicht] verständlich machen will" (Duden. Deutsches Universal Wörterbuch. A-Z. 1996: 616)². Gleichnis es "parábola", y la parábola como género discursivo posee un carácter de comparación, de extensa metáfora entre dos mundos, como trasvase analógico de significados y de potenciales de sentido desde uno hasta el otro.

Un problema en la traducción de Fernández del Valle y Carvajal consiste en que unendlich Toten no es "infinitos muertos", pues éstos serían en alemán unendliche Tote. En este segmento unendlich es adverbio, no adjetivo, y por eso carece de marcas de género y de número, mientras que Toten muestra la $n$ de un adjetivo, ya que en efecto es un adjetivo modificado por un adverbio y no un sustantivo modificado por un adjetivo.

A Rilke le interesaba muy poco el número de los muertos; lo que le importó por lo menos desde el Réquiem para su amiga Paula Modersohn, de 1908, fue la posible presencia de los muertos queridos en la conciencia y en el transcurso de los vivos. Hay para él una crucial diferencia entre los que son ya infinitamente muertos y aquellos muertos que por una razón u otra aún no son del todo difuntos. En esta última circunstancia se encontraba Paula un año después de su muerte en 1907, cuando en 1908 le hizo sentir al poeta su inquieta presencia ${ }^{3}$. Los muertos jóvenes que visitan la Ciudad del Dolor en la décima elegía son asimismo, en tanto que muertos recientes, muertos que no están infinitamente muertos.

Gonzalo Torrente Ballester y Metchild von Hesse Podewils traducen Gleichnis como "parábola". Ahora bien, pese a tratarse de un dúo muy adecuado, pues Torren-

\footnotetext{
${ }^{2}$ Una narración breve, gráfica [plástica], que quiere hace comprensible un pensamiento o proceso abstracto por medio de la comparación con una acción concreta, visible [con intención formativa].

${ }^{3}$ Reviso el momento del virtual encuentro entre el poeta vivo y la amiga difunta en "El réquiem en Rainer María Rilke. Género de vida y muerte entre el tombeau, el testamento, la elegía y el epitafio" (Vital 2012: 9-29).
} 
te era hispanohablante nativo y Metchild era germanohablante nativa, ninguno de los dos captó que la primera oración es condicional y que por lo tanto se relaciona con la siguiente; por la misma razón tradujeron como copretérito ("señalaban" y "pensaban") lo que es hipotético o equivalente a pospretérito ("señalarían" y "pensarían"):

Pero ellos, los infinitos muertos, despertarían en nosotros

mira, ellos señalaban quizá las candelillas colgantes

[una parábola;

de la avellana vacía, o pensaban en lluvia

que cae en primavera sobre el reino de la tierra oscura.

Y nosotros, que pensamos en felicidad creciente, sentiríamos la misma conmoción que casi nos consterna cuando cae un cosa feliz .

Los traductores tampoco captaron el importante matiz entre "infinitos muertos" e "infinitamente muertos".

La traducción de Félix Dauajare conlleva más de un alejamiento del sentido original, propuesto por Rilke:

Pero si los muertos infinitos evocaran en nosotros

ve, señalarían, quizá, a las candelilla del vacío

[una metáfora;

avellano que cuelgan, $o$

pensarían en la lluvia que cae en el oscuro reino

[de la tierra en primavera.

Y nosotros, que en ascendente felicidad

pensamos, sentimos la emoción

que casi nos sobresalta

cuando cae un afortunado (Elegías de Duino 2009: 79)

En primer término, traduce como "infinitos muertos" lo que debe verterse como "infinitamente muertos". Luego, incurre en el presente de indicativo de "sentimos" en vez del pospretérito o hipotético de "sentiríamos". Por último, elige "un afortunado" para traducir "ein Glückliches", cuya "s" final marca claramente un neutro; "un afortunado" traduciría más bien "ein Glücklicher".

\footnotetext{
4 Reproducido en Jiménez / Vital / Zepeda 2006: 214. Un ejemplar de la edición original se encuentra en la biblioteca del autor de Pedro Páramo. Dicha edición apareció en Madrid el año de 1946 bajo el sello de Nueva Época (ibídem: 52). Una parte importante de los verbos en alemán no distinguen entre el pretérito y lo que en español es el pospretérito: el significante es idéntico; Torrente y Hesse se confundieron porque ninguno de los dos verbos empleados por Rilke hace esa distinción, que sí aparece en verbos más usuales como sein y haben.
} 
En los años cuarenta, justo cuando empezaba a concebir el mundo narrable y el tono de El Llano en llamas (1953) y de Pedro Páramo (1955), un Juan Rulfo de 27, 28 años de edad, se preparaba transcribiendo y a veces recreando poemas de sus autores preferidos. Sin pensar nunca en publicarlas, transcribió y les hizo algunas variaciones a las diez Elegías de Duino a partir de la versión que el escritor exiliado español Juan José Domenchina había hecho con base en traducciones del alemán al francés. He aquí la versión de Domenchina, con algunas variantes de Rulfo:

Mas si los infinitamente muertos

hicieran nacer en nosotros un símbolo,

mira, señalarían tal vez esos amentos

que cuelgan de los avellanos exhaustos,

o bien nos mostrarían la lluvia que cae sobre

la oscura tierra en primavera.

Y nosotros, que siempre hemos esperado mirar

cómo asciende

la felicidad,

sentiríamos el enternecimiento

que casi nos trastorna

cuando la dicha cae (214).

Como conclusión de esta primera parte, puede decirse que si traducir es un ejercicio de hermenéutica literaria y de literatura comparada, compulsar traducciones es asimismo un ejercicio en las dos direcciones, un ejercicio de interpretación-comprensión y de compenetración con los textos.

\section{Brecht}

Mucho menos conocidas que las Duineser Elegien, aunque también ya traducidas, son las Bukower Elegien, del célebre dramaturgo alemán Bertolt Brecht. Se trata de (según la edición) entre 21 y 24 poemas breves, que no tienen ninguna de las marcas típicas del género de la elegía, como no sea cierta melancolía en algunos de sus versos. Puesto que Brecht murió en 1956 y las Buckower Elegien se editaron por fin juntas en 1964, podría llegar a pensarse que el responsable del título sería el editor Siegfried Unseld, no Brecht. ${ }^{5}$ De hecho, Unseld jugó verbalmente y planteó que se trataba de unas elegías bucólicas, pues Buckowlische Elegien suena precisamente así. El juego de Unseld partía del hecho de que la casa de descanso del poeta se encontraba en Buckow, un pueblito a las afueras de Berlín Este, y aún hoy es sitio de peregrinaje para los admiradores del autor de Mutter Courage y de la Dreigroschen Oper. Sin embargo, fue el

\footnotetext{
5 Debo esta observación al doctor Dietrich Rall. Él mismo me proporcionó toda la información acerca de la edición del libro de Brecht, en especial la certeza de que fue el dramaturgo quien personalmente le puso el título a su breve libro.
} 
propio Brecht quien ya en 1954 jugó con ese título, el cual establece una inmediata e irónica intertextualidad con las Duineser Elegien, de Rilke:

Unter den verstörenden Eindrücken des 17. Juni 1953 entstand, hauptsächlich im Juli und August, eine Reihe von Gedichten, die Brecht in einer Mappe als «Buckower Elegien» sammelte. [El título original es, por tanto, de Brecht mismo.] Sechs der Gedichte erschienen sogleich in der Zeitschrift Sinn und Form und dann im ersten Halbjahr 1954 in Versuchen. Zu weiteren 17 Gedichten, eingeschlossen das Motto-Gedicht, existieren Abschriften des Autors auf Einzelblättern vom zweiten Halbjahr $1954 .^{6}$

No me es dable rastrear la posible ironía de Brecht frente a Rilke (o quizá un homenaje irónico, una evocación con tinte de distanciado humor) más allá de este título. En todo caso, nada es menos semejante a las Elegías de Duino que las Elegías de Buckow. Ahora bien, si la eventual ironía se refería a la falta de relación con lo concreto contemporáneo en el libro de Rilke, habría que notar que este autor estaba haciendo entre 1912 y 1922 una lectura en clave de elementos fundamentales de la condición humana en ese tiempo, hace cien años, poco más, poco menos, y que este poemario aparentemente intemporal y ontológico también era, de manera sutil, muy específico ante su época concreta y anticipaba reflexiones de Martín Heidegger en Sein und Zeit, de 1927. Y no sólo de Heidegger. No sólo temas relacionados con las especificidades de la época: en plenas elegías, al final, hay una sorpresiva y sorprendente definición del dinero, objeto y mercancía que condensa buena parte de las decisiones no sólo económicas, sino históricas:

wie das Geld sich vermehrt, anatomisch, nicht zur Belustigung nur: der Geschlechtsteil des Geldes (480).

Ferreiro Alemparte traduce así:

cómo el dinero se multiplica anatómicamente, no sólo como simple regocijo: el órgano sexual del dinero (237).

Asombra y resulta sugerente la definición del dinero como órgano sexual. La traducción de Torrente Ballester y Von Hesse Podewils es más audaz:

cómo se multiplica el dinero, anatómicamente, no sólo para la diversión: el falo del dinero (210). ${ }^{7}$

\footnotetext{
${ }^{6}$ Bertolt Brechts Buckower Elegien. Mit Kommentaren von Jan Knopf, p. 121s. Surgidas en medio de las devastadoras impresiones del 17 de junio de 1953, fundamentalmente en julio y agosto, Bertolt Brecht las reunió en una carpeta con el título de 'Buckower Elegien'. Seis de los poemas aparecieron pronto en la revista Sinn und Form [Sentido y forma] y luego, en el primer semestre de 1954, en la revista Versuch [Ensayo, intento]. De los restantes 17 poemas, incluido el poema-lema, existen autógrafos del autor en hojas sueltas del segundo semestre de 1954 .

7 Ahora bien, Geschlechtsteil no compromete una sexualidad masculina. Literalmente es "parte del sexo", como cuando en español decimos "las partes"; se trata de un término aglutinado que conviene traducir simplemente como "órgano sexual".
} 
Rilke sitúa esta definición en el centro de la parte espectacular (la feria, der Jahrmarkt) de la ciudad del dolor (die Leid-Stadt). Queda también claro que el dinero se relaciona con los adultos. El poeta establece este vínculo como diversión, pero no sólo como diversión. Y tiene poder multiplicador. Genésico o por lo menos reproductivo. Con estas líneas de la décima elegía, Rilke prefigura la actual sociedad del espectáculo. Y al otro lado está lo real, donde los niños juegan, donde los amantes se toman y donde los perros tienen naturaleza. Es como si de una parte, en el espectáculo, en la diversión del dinero-sexo (y no sólo diversión), estuvieran los adultos, y de la otra parte, en lo real, sin verse, aunque muy cerca, estuvieran los niños, los amantes y los animales, más valorados todos ellos por Rilke De manera provocativa, el poeta plantea una visión muy propia, muy aguda y muy insólita, del mundo de los vivos, justo cuando va a hacer que un adolescente se adentre en el mundo de los muertos. Lo hace ciertamente desde la perspectiva del poeta, que no es ni antropólogo ni filósofo ni historiador ni economista, pero sí un provocador de todos ellos, un alentador y un factor de ruptura de los automatismos de la percepción. Rilke va desde luego más allá y propone un mundo original, a la vez sugestivo y orgánico, donde lo histórico queda sumergido en lo ontológico; por esto último en Rilke prácticamente no hay fechas ni referencias a hechos históricos o de época.

Existe otro pasaje en las Elegías que revela una misma, vasta comprensión de los movimientos históricos; se trata del pasaje de la séptima elegía en que la voz lírica dice:

Jede dumpfe Umkehr der Welt hat solche Enterbte, denen das Frühere nicht und noch nicht

\section{[das Nächste gehört. ${ }^{8}$}

Rilke sitúa esta definición en el centro de la elegía considerada menos melancólica y más eufórica.

En contraste con un Rilke sin fechas (hay por allí un "Autorretrato de 1906" como excepción), el poema más famoso de las Buckower Elegien incluye una fecha muy explícita, precisamente la del 17 de junio, sin necesidad de incluir el año (1953), muy conocido por casi cualquier alemán, sobre todo antes de la caída del Muro de Berlín en 1989:

\section{DIE LÖSUNG}

Nach dem Aufstand des 17. Juni

Liess der Sekretär des Schriftstellersverbands

In der Stalinallee Flügblätter verteilen

Auf denen zu lesen war, dass das Volk

Das Vertrauen der Regierung verscherzt habe

Und es nur durch verdoppelte Arbeit

\footnotetext{
${ }^{8}$ Ferreiro Alemparte traduce: "Cada giro insensible del mundo tiene tales desheredados / que no poseen el pasado ni tampoco lo inmediato venidero" (Nueva antología poética, ed. cit.: 228).
} 
Zurückerobern könne. Wäre es da

Nicht doch einfacher, die Regierung

Löste das Volk auf und

Wählte ein anderes? (Gesammelte Gedichte 1976: 1009-1010)

Los poetas mexicanos Alberto Blanco y Pura López Colomé realizaron en 1990 una traducción del librito de Brecht y rindieron de la siguiente manera "Die Lösung":

\author{
LA SOLUCIÓN \\ Después del levantamiento del 17 de junio, \\ el secretario de la Asociación de Escritores \\ hizo distribuir volantes por la Avenida Stalin \\ en los que constaba que el pueblo \\ había defraudado la confianza del gobierno \\ y que sólo la podría reconquistar \\ redoblando sus esfuerzos. ¿No habría sido \\ mejor para el gobierno en todo caso \\ dispersar al pueblo \\ y elegir otro? (Las visiones y los tiempos oscuros 1989: 125-126)
}

Ahora bien, se trata de un epigrama, más que de una elegía. Tendríamos entonces una oportunidad de hacer aquí un análisis con respecto a los géneros discursivos y a la transgresión que Brecht parece estar realizando al respecto: la tradición elegíaca en alemán cuenta con estaciones tan importantes como Johann Wolfgang von Goethe (sus Elegías romanas son en buena medida festivas, con su célebre quinta elegía, claramente gozosa de la plenitud erótica) y Friedrich Hölderlin. Rilke tuvo no sólo que leer y releer a estos dos grandes poetas, sino reconciliarse a la distancia con Goethe, antes de darse la oportunidad de encontrar las cadencias adecuadas para sus propias Elegías. En todo caso -fueran festivas y eróticas o melancólicas, fuese que rescataran del mundo antiguo la alegría de vivir o la gravedad del existir-, las elegías de Goethe, de Hölderlin y de Rilke poseen dos rasgos decisivos en común, uno formal y uno de contenido: 1) están escritas en verso de largo aliento, incluso con sonoridades griegas, y 2) nunca se remiten al tiempo público inmediato concreto, al tiempo político contemporáneo, y menos aun establecen como referentes y como mecanismos de coherencia fechas específicas marcadas por su impacto social y mediático. El verso corto y contundente y la referencia a lo concreto (incluido en lo concreto un individuo, que en este caso es el secretario de la burocrática asociación de escritores) son rasgos propios del epigrama, así que en este caso no hay duda acerca de la filiación concreta de este poema y de la transgresión que practicaba Brecht al insertarlo en un grupo de poemas cubiertos bajo el título de Elegías de Buckow (otros más son también epigramáticos, otros tienen cierto tinte bucólico, otros son sentenciosos, casi todos van envueltos, eso sí, en cierta melancolía no ajena a las elegías tanto de Hölderlin como de Rilke). 
Aludo ahora a una posible traducción más contundente de este poema, más cercana a la ironía del autor. Esta propuesta de traducción puede ser mejor comprendida en países con tradición parlamentaria. La variante se reduce exclusivamente al final:

\author{
¿No habría sido \\ mejor para el gobierno en todo caso \\ disolver al pueblo \\ y convocar a elecciones?
}

El verbo clave, auflösen, significa efectivamente "disolver” en el léxico político jurídico democrático, como cuando se dice "disolver el parlamento". Se relaciona además con lösen, "resolver" o "disolver", y con Lösung, "solución”.

El poema incluye una doble ironía obvia: contra el secretario y contra el gobierno. Incluye dos posibles ironías mucho menos obvias: contra la situación general y, en este marco, también contra el propio autor.

\title{
3. Grass
}

Gracias a otro poeta y dramaturgo alemán (y novelista, galardonado con el Nobel en 1999), Günter Grass, podemos acercarnos a una posible sustentación de esta hipótesis acerca de un segundo par de ironías en el texto. Grass trabajó tan intensamente con el papel de Brecht aquel 17 de junio de 1953 que le dedicó su primera pieza dramática importante y le dedicó un escrito esclarecedor de su propia postura ante Brecht y ante la redacción de esta pieza, titulada Die Plebejer proben den Aufstand, Los plebeyos ensayan la rebelión, de 1966.

Grass pilló a Brecht en el momento más contradictorio de su vida. He aquí una somera reconstrucción de aquellas jornadas: en el contexto de la Guerra fría, el régimen de la República Democrática Alemana había resuelto dedicar más recursos económicos al rearme que a la agricultura, más al acero de las armas y de los grandes bloques de las oficinas que a la madera (presumiblemente bambú) de la sabiduría popular (Brecht emplea la oposición entre hierro y madera en otro poema de Buckower Elegien para decir que lo hecho de madera se dobla en la tormenta y resiste y vive más que el acero; la sabiduría oriental aprecia esta virtud, especialmente nítida en el bambú) (Gesammelte Gedichte: 1012; Las visiones y los tiempos oscuros: 128-129).

Consecuencias de esta decisión tomada en Moscú fueron el parcial abandono del campo, el hambre literal y el hondo descontento de la población alemana oriental. Aun sin las redes cibernéticas del siglo XXI, los trabajadores de la construcción de la capital se organizaron con trabajadores de otros rubros y de otras ciudades y en pocas horas realizaron protestas que culminaron con la vasta manifestación por la avenida Stalin, la más orgullosa de Berlín Este, el 17 de junio de 1953. Presa del pánico, la cúpula burocrática de este país del pueblo y para el pueblo no supo qué hacer cuando el pueblo se alzó pacíficamente para reclamar la derogación de la Nor- 
merhöhung (que Brecht resumió en el poema como verdoppelte Arbeit, "trabajo duplicado") y para pedir que la República Democrática Alemana fuera mínimamente democrática. La Normerhöhung era un término burocrático, literalmente "elevación de la norma", que disimulaba la tajante exigencia de trabajar el doble por el mismo sueldo. La feroz represión corrió a cargo de los tanques soviéticos, y ello sirvió a la nomenclatura de Moscú para enviar el mensaje de que tras la muerte de Stalin, ocurrida apenas unos meses antes, las cosas seguirían igual al otro lado de la cortina de hierro: Alemania oriental era uno más de los traspatios del Kremlin.

Justo ese día Brecht estaba ensayando en el teatro la puesta en escena de una pieza de algún colega; sobre la mesa de casa había dejado sus apuntes para una adaptación (que hoy quizá tenemos el derecho a llamar populista) del Coriolano, de William Shakespeare. Grass captó el dramatismo y el hamletiano juego de espejos y aprovechó las dos circunstancias para llamar a examen a su colega y predecesor y para darnos el indicio de un cambio de época entre el horizonte de Brecht (moderno típico, de índole materialista) y el horizonte contemporáneo (escéptico, tal vez postmoderno) de Grass. A fin de hacer posible la pieza y de intensificar el dramatismo, así como el juego intertextual, el autor de El tambor de hojalata modificó el dato de la obra que ese día ensayaba Brecht y sustituyó al colega hoy olvidado por el Coriolano de Shakespeare.

El Brecht de carne y hueso se vio atrapado ese día entre, por una parte, sus responsabilidades como dramaturgo y director teatral consentido por el régimen y respetado por la gente y, por otra, sus deberes con esta misma gente, representada 1) por las personas que expusieron la vida durante esa jornada, 2) por los actores que representaban a los plebeyos en el ensayo del Brecht teatralizado por Grass y 3) por los personajes de esa misma pieza que irrumpen en las tablas e interrumpen el ensayo para pedirle al Jefe (así denomina Grass al Brecht teatralizado) que abogue por ellos escribiendo una carta a los dirigentes del partido y de la república.

El Brecht de Grass se comporta como un jefe y juega como gato y como ratón con el poder meramente simbólico de cualquier carta que se escribiera a las autoridades, a las cuales él mismo representa, pues él también es un jefe. Brecht es entonces doblemente representativo: es representativo de la autoridad y del pueblo, cuya emancipación ha poetizado y dramatizado durante años. La doble representación le pesa demasiado al Brecht de Grass; ahora bien, este Brecht teatralizado asume una actitud irónica frente al pueblo, similar a la que asume Hamlet con su tío asesino y usurpador y con su madre adúltera y similar a la que asume Coriolano con el pueblo que habrá de elegirlo como cónsul en la pieza de Shakespeare. El Brecht de carne y hueso escribió en efecto cartas. En ellas pedía moderación al régimen, a la vez que elogiaba sin asomo de duda la importancia de la cúpula dirigente de este país de trabajadores. La cúpula difundió sólo los párrafos elogiosos de Brecht y dejó a éste en una posición vulnerable.

Las Buckower Elegien se refugian en algunos sueños, en la crítica a los viejos nazis hoy reinsertados, así como en la impaciencia y en los enigmas sentenciosos. "Die Lösung" podría cifrar una ironía contra toda la situación, típicamente contradictoria, en la cual se vio envuelto e incluido el propio yo. Es verdad que la auto-ironía no es precisamente una marca definitoria del epigrama, y aun así se 
trata de la única referencia explícita importante que el autor hizo de la situación, por lo que ha de verse la ironía del texto como señal de la ironía del autor frente a todas las circunstancias, frente a todo aquel hecho histórico. El propio silencio de Brecht, apenas interrumpido por este breve epigrama, fue una manera de pasar la página ante un acontecimiento tan difícil de digerir, bañándolas sólo con una tenue capa de ironía.

Pero si ésa era su intención, Grass no le dio permiso de consumarla. Retomó el tema en los años sesenta, justo cuando el teatro jugaba un papel preponderante en la renovación de la vida letrada alemana y por ejemplo la teoría de la recepción nacía al calor de las experiencias del teatro universitario de la época, con un público sumamente participativo, tal y como lo quería el autor de Mutter Courage.

De hecho, el tema de esta pieza teatral de Grass define un principio irrenunciable del carácter y de la ética (de la ontología y de la deontología) del novelista: no permitir que se guarde silencio acerca de todo lo que no debe ocultarse. Tanto más cruel fue en aquel caso esta decisión de Grass porque al elegir el teatro jugaba con Brecht en el propio terreno de este último y con el mismo tipo de público.

Hasta nuestras días, consagrado y ya muy mayor, Grass conserva este principio aun a costa de incomodar a poderes tan grandes como el de Israel y la comunidad judía. En abril de 2012 el poema "Was gesagt werden muss", "Lo que debe ser dicho" o "Lo que debe decirse", comienza hablando del malestar del poeta por haber callado tanto tiempo sobre un asunto tan delicado como el peligro atómico que se cierne sobre la humanidad en estos meses a causa de las tensiones entre Israel e Irán. A diferencia de casi toda la poesía de Grass, el texto resultó polémico en buena medida por ser ideológico, esto es, por no ser como casi todos los demás poemas del autor, que son indirectos, oblicuos, herméticos incluso, muchas veces desprovistos de los mecanismos de coherencia de los discursos habituales; "Was gesagt werden muss" nació como un texto muy directo y por ende muy parcial, pues era imposible que tratara tan grave asunto público con la totalidad de sus ramificaciones pasadas, presentes y futuras. El poema apareció en nuestro idioma al día siguiente gracias a los presurosos oficios del traductor oficial de Grass, Miguel Sainz. Precisamente por ser un texto muy directo, no ofrece mayores enigmas ni dificultades a la traducción, y Sainz sólo se permitió modificarle al texto la división en estrofas de que Grass lo había provisto.

Mucho más enigmático e indirecto, sutil y creativo es el poema "Politische Landschadt", "Paisaje político", con el cual terminaré este sucinto repaso de las traducciones al español de tres importantísimos poetas de lengua alemana. Aquí no contamos con una traducción, así que el Seminario de Estudios Literarios, Poesía y política, de la Facultad de Filosofía y Letras y del Instituto de Investigaciones Filológicas de la Universidad Nacional Autónoma de México se encargó de ofrecer una propuesta tentativa; el poema apareció en Ausgefragt, del año de 1967; es decir, proviene de la misma época en que se concibió y apareció Los plebeyos ensayan la rebelión:

Uns, Geschädigten, denen das Wissen

Mühe macht beim Verlernen, 
ordnet die Geografie wirre Geschichte:

Seitlich Adenau und bis an das Flüsschen Hunte, zwischen Galen und Frings, buchen die Sozis kleine Gewinne, mühen sich ab beim Verlernen.

Doch immerfort tagt am Wannsee die Konferenz; immerfort werden in Eifellava, Basalt, in grauen Globke - nie wieder in Travertin die Kommentare gezwungen.

Denn das soll bleiben bleiben und sich nie mehr vertagen dürfen: von der Jaksch bis zur Veba, unausgesetzt wird zuendegedacht. Schuld und die Forstwirtschaft oder was nachwächst: Schonungen geben dem Land Enge und Hoffnung, damit Nutzholz und eine neue Generation schon morgen vergisst, wie verschuldet, wie abgeholzt Schwarzwälder waren.

Schön ist das Land und Natur stützt die Kurse und Reiseprospekte, denn ein Blick bis zur Elbe oder vom Bockberg nach drüben zum Marx wie sie sich abschirmen, wie wir uns abschirmen -, wo immer sich ernste Berge im Wege stehn und der Gedanke nicht flügge wird, lohnen sich Blicke vom Blessing über den Rhein. $\mathrm{O}$ ihr linken und rechten Nebenflüsse:

die Barzel fliesst in die Wehner.

Abwässer speisen das Sein.

Grauwacke, Rehwinkel, laubgesägt Tannen, Karst, Abs und Kulmbacher Bier, altfränkische Wolken über dem Heideggerland ${ }^{9}$ (Die Gedichte 1955-1986 1988: 192-193).

A nosotros, los dañados, a quienes el saber ocasiona molestias cuando desaprendemos, la geografía nos ordena la confusa historia: al lado del Adenau y hasta el riachuelo Hunte, entre Galen y Frings, los sozis se apuntan pequeñas victorias, se esfuerzan al máximo por desaprender.

Pero la Conferencia sigue sesionando en el Wannsee;

\footnotetext{
${ }^{9}$ Los traductores agradecen la revisión de Dietrich Rall.
} 
se siguen forzando los comentarios

en lava del Eifel, basalto,

en Globke gris - nunca más en Travertino.

Pues esto tiene que perdurar perdurar

y ya no tiene derecho a aplazarse:

del Jaksch hasta el Veba

se razona hasta el fin sin interrupción.

Deuda y economía forestal

o lo que retoña: cotos

le dan a la tierra angostura y esperanza

para que la madera útil y una nueva generación

ya mañana mismo olvide

qué endeudadas, qué taladas

quedaron las Selvas Negras.

Bella es la tierra, y la naturaleza

apoya los cursos y los folletos de viaje,

pues una mirada hasta el Elba

o desde el Bockberg hasta más allá del Marx

-cómo se blindan ellos, cómo nos blindamos nosotros-,

donde siempre montes serios se interponen en el camino

y el pensamiento no madura,

se ameritan miradas

del Blessing sobre el Rhin.

Oh, ustedes, afluentes de izquierda y derecha:

el Barzel fluye hacia el Wehner.

Desagües alimentan el ser.

Grauwacke, Rehwinkel, abetos segados,

azadón, cerveza Abs y Kulbacher,

nubes de antiguos francos sobre Heideggerland.

El mérito del poema consiste en que mezcla nombres geográficos y nombres políticos. Tiene entonces una estructura sólida y original.

Posee otra característica que lo acerca al epigrama de Brecht: se inmiscuye con asuntos del momento, de modo que se vuelve muy legible en una recepción inicial y se vuelve muy arduo en las subsiguientes recepciones o en recepciones y traducciones fuera del horizonte político inicial. Esta doble condición caracteriza una parte no despreciable de la poesía tanto de Brecht como de Grass: arriesgarse a tomar el discurso literario como un instrumento para incidir en las discusiones de la época. Una diferencia consiste en que en el muy reciente poema sobre el poder nuclear de Israel Grass decidió no colocar ninguna pantalla poético-retórica, decidió no construir ninguna mediación que hiciera del discurso literario un discurso indirecto o, si se quiere, sesgado, mediado, incluso duplicado y espejeado por factores como la ironía o como la fusión en un mismo terreno de nombres geográficos y nombres históricos. Apenas insertó una frase patética: decir que escribe con su última tinta. Esta inserción sería cursi si no fuera porque Grass es uno de los escritores menos dados al patetismo que uno pudiera concebir, y ha sido más bien un autor lúdico, irreverente, tumultuoso; por ello este rasgo repentino de patetismo debería tomársele 
como el empleo de un tono que por lo insólito en él busca provocar el máximo efecto posible de autenticidad y de captatio benevolentiae, habida cuenta -además- de que muy poca captatio benevolentiae hay en toda la literatura de Grass.

Entre los juegos que practicó Grass en "Politische Landschaft" se encuentra el hecho de insertar en una lista de piedras para grabar (como el basalto y el mármol travertino) el nombre de la eminencia gris del régimen de Konrad Adenauer, considerado aún hoy el padre de la República Federal de Alemania. El gris Globke no era un tipo de piedra, sino un individuo que en su historial tenía el haber sido un furibundo antisemita y el haber colaborado en puestos nada despreciables de la Alemania nazi. De ese modo, Grass se arriesgaba poniendo al desnudo un hecho estremecedor para la aún joven República Federal de Alemania: el poderío de un gigantesco chapulín político que no sólo había sobrevivido a la guerra y a la inmediata posguerra, sino que además se había incrustado en los más altos círculos de la nueva democracia, para cuyo nacimiento se habían sacrificado cientos y cientos de miles de vidas. Quien quiera acusar de antisemita a Grass por sus versos de abril de 2012, debería tomar en cuenta ya tan sólo "Politische Landschaft" para admitir que en él no se trata de atacar a tal o cual persona, a tal o cual pueblo o país, sino de delatar con los más versátiles instrumentos literarios los máximos peligros para la convivencia planetaria. Luego de la polémica de abril de 2012, Grass incita ahora, en su nuevo libro de poemas, a una variante de la resistencia civil: invita a vulnerar y a evidenciar las páginas cibernéticas de todos los poderes atómicos del mundo con el fin de que desde las redes sociales se contrarreste el riesgo de una conflagración mundial definitiva causada por el incremento indiscriminado e impune de las tecnologías para la hecatombe.

\section{Referencias bibliográficas}

\section{Originales}

BRECHT, B., Bertolt Brechts Buckower Elegien. Mit Kommentaren von Jan Knopf. Frankfurt: Suhrkamp 1986.

BRECHT, B., «Buckower Elegien», Sinn und Form 6 (1953).

BRECHT, B., Gesammelte Gedichte. Frankfurt: Suhrkamp 1976, vol. 3.

Grass, G., Die Gedichte. 1955-1986. Darmstadt: Luchterhand 1988.

Rilke, R. M., Duineser Elegien, en: Werke. Ed. de Ernst Zinn. 2a reimpresión. Frankfurt: Insel 1966 (1955), vol. 2.

\section{Traducciones}

Brecht, B., Las visiones y los tiempos oscuros. Trad. de Pura López Colomé y Alberto Blanco. México: Universidad Nacional Autónoma de México 1989.

Rilke, R. M., Elegías de Duino. Traducción de Félix Dauajare. Presentación de José María Espinasa. México: Ediciones sin nombre 2009.

Rilke, R. M., Elegías de Duino. Trad. de Lorenza Fernández del Valle y Juan Carvajal. México: Universidad Nacional Autónoma de México 2004. 
Rilke, R. M., El libro de horas. Trad. y prólogo de Federico Bermúdez-Cañete. Madrid: Hiperión 2005 (1905).

RiLKe, R. M., Nueva antología poética. Trad. de Jaime Ferreiro Alemparte. Prólogo de Jaime Siles. 4a reimpresión. Madrid: Espasa Calpe 2008 (1999).

\section{Bibliografía general}

DERRIDA, J., Béliers. Le dialogue interrompu: entre deux infinis, le poème. París: Editions Galilée 2003.

Duden. Deutsches Universal Wörterbuch. A- Z. Mannheim / Leipzig / Wien / Zürich: Dudenverlag 1996.

Jiménez, V. / Vital, A. / ZePeda, J. (eds.), Tríptico para Juan Rulfo. Poesía, fotografía, crítica. México: Editorial RM et al. 2006.

DE MAN, P., «Rilke (tropos)», en: Alegorías de la lectura. Traducción de Enrique Lynch. Barcelona: Lumen 1990 (1979).

Quevedo, A., Derrida. De Foucault a Derrida. Pamplona: Universidad de Navarra www.jacquesderrida.com.ar/comentarios/quevedo/htm, consulta del 19 de abril de 2012.

VITAL, A., «El réquiem en Rainer María Rilke. Género de vida y muerte entre el tombeau, el testamento, la elegía y el epitafio», en: Rilke, Rulfo. México: Samsara 2012, 9-29. 